\title{
Unusual Failure of a Rim Fire Cartridge Brass Casing
}

\author{
F.E. Schmidt, Jr., * and J.L. McDougall ** \\ *Engineering Systems Inc., 4215 Campus Drive, Aurora, IL 60504 \\ **Engineering Systems Inc., 6230 Regency Parkway, Norcross, GA 30071
}

Conventional .22 (twenty two caliber) rim fire ammunition is used as one of the first experiences in shooting sports. Typical BSA/GSA Scout camps and other recreational organizations familiarize young shooters with the ten commandments of firearm handling. The ammunition is also important, especially the initial condition before inserting in the battery (breech/action) of the handgun or rifle. In fact .22 RF ammo can be found typically around the house and garage loose in drawers, tool boxes, and jars with other non-ammo items. Herein is the more typical concern, i.e. .22 RF casings that have been corroded by various dangerous household products: glass cleaners with ammonia, brass polishing or metal cleaners, pool chemicals, and occasionally salt. In the presence of humidity the cartridge rim which is highly metal-worked during manufacturing, can become the victim of Stress Corrosion Cracking (SCC) or pitting and become unsuitable for use.

In this matter a failure analysis of a standard .22 RF did not exhibit a corrosion deficiency, but rather exhibited all the indicia of a high pressure failure. The visual inspection shows the external case head to be extruded into the rim firing pin slot and "obturation" of the cylindrical casing wall. Stereo optical examination (LOM) shows true ductile rupture metallurgical characteristics around the complete rim circumference. Scanning Electron Microscopy (SEM) indicated shear dimple rupture. Energy Dispersive Spectroscopy (EDS) analyses did not find any corrosion products consistence with a SCC or pitting failure mode.

In conclusion, macroscopic examination, metallography, and electron microscopy were used to completely rule out the probability that a chemical agent had instigated this RF cartridge case failure. The firearm in question was checked for proper head space with a Go - No Go measurement and action/breech was clear of any obstacles.

FIG. 1. Stereo Optical Micrograph of a side profile view of the RF casing $(\sim 10 \mathrm{X})$.

FIG. 2. Stereo Optical Micrograph of mouth of casing, indicates proper bullet insertion $(\sim 15 \mathrm{X})$.

FIG. 3. Micrograph of Case Head where Brass is extruded into the Firing Pin Slot $(\sim 40 \mathrm{X})$.

FIG. 4. Micrograph of inside Case Head, indicates uniform deformation and tearing $(\sim 10 \mathrm{X})$.

FIG. 5 SEM Micrograph of inside region of Case Head, ductile - rupture (shear mode) $(\sim 25 \mathrm{X})$.

FIG. 6. SEM Micrograph of shear ruptured case rim, typical, 360 degrees rotation $(\sim 400 \mathrm{X})$.

General References: AFTE technical terminology, Glossary, third Edition, 1994. SAAMI Technical Specifications for Go - No Go and .22 RF casing dimensions. "An Atlas of Metal Damage": by Lothar Engel, and Hermann Klingele, translated by Stewart Murray Wolfe Publishing Ltd., 1981. 

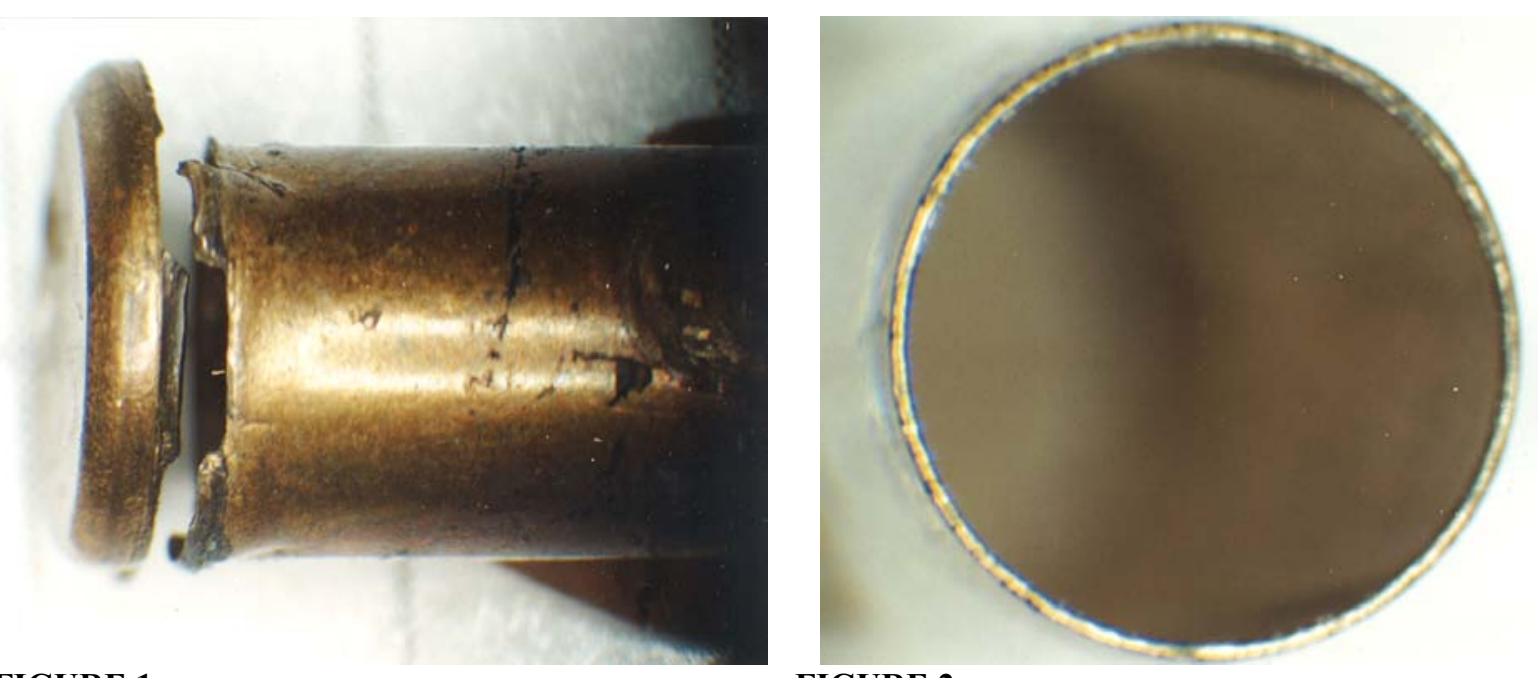

\section{FIGURE 1}

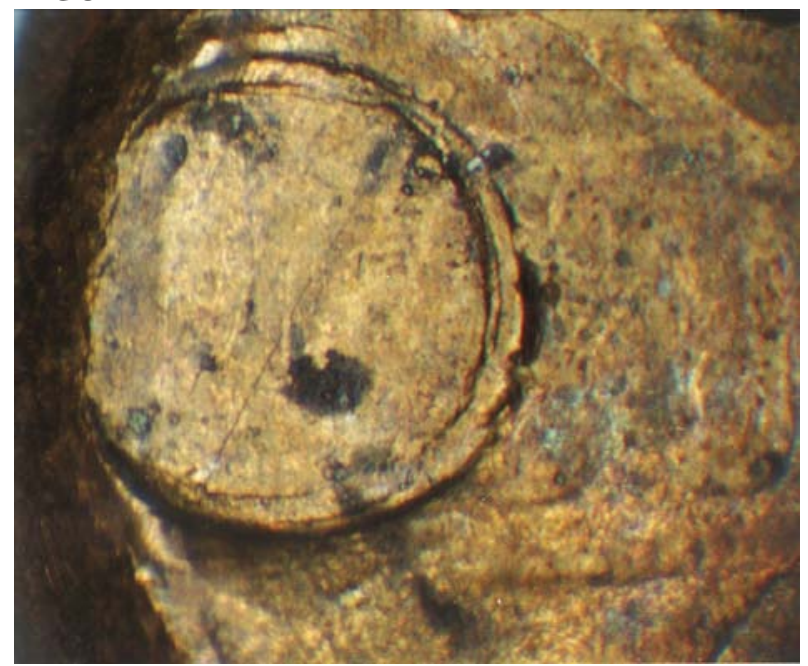

FIGURE 3

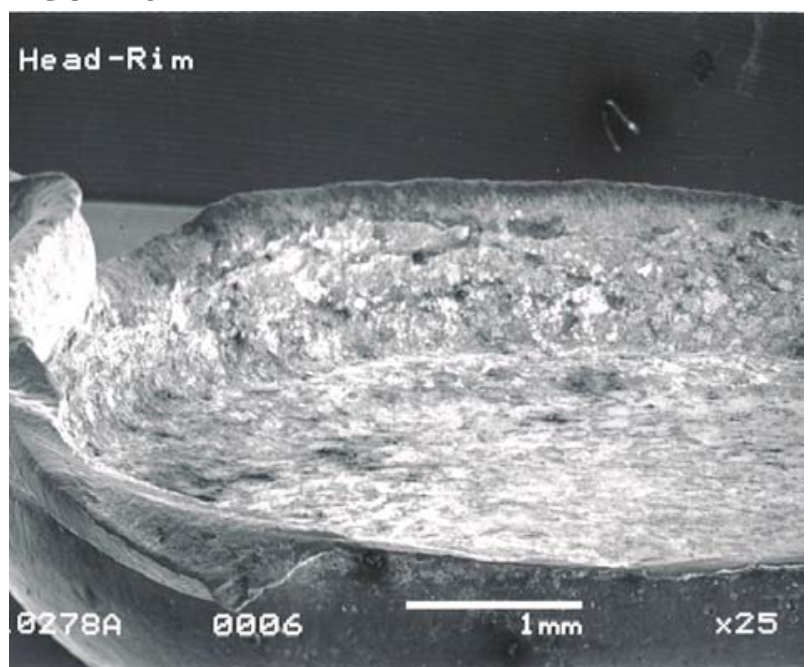

FIGURE 2

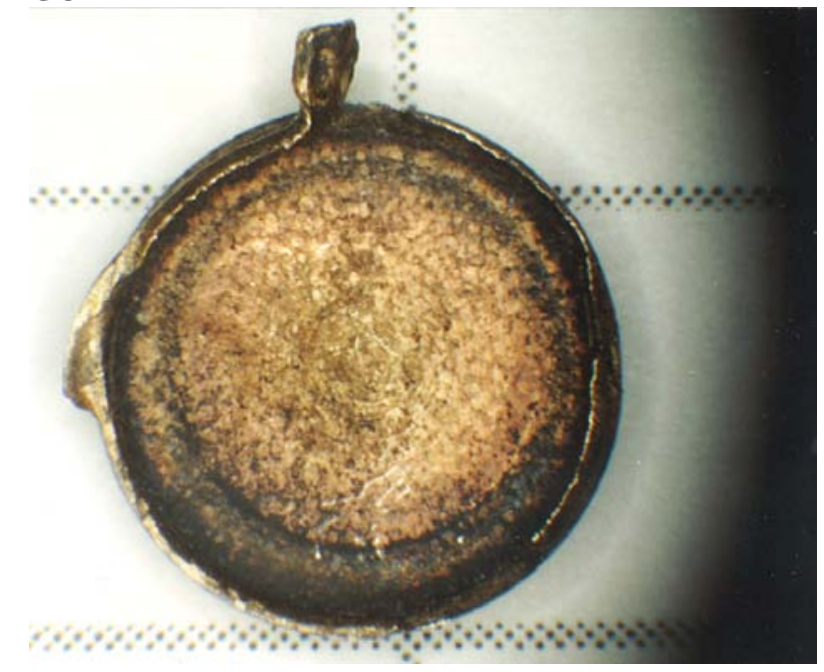

FIGURE 4 